\title{
The Antecedents of Knowledge Sharing in Public Sector
}

\author{
Igfar Reza Ahmadi ${ }^{1, *} \&$ Riani Rachmawati ${ }^{2}$
}

\author{
${ }^{1}$ University of Indonesia, Jakarta, Indonesia \\ ${ }^{2}$ University of Indonesia, Jakarta, Indonesia \\ * Corresponding author. Email: igfar.reza@gmail.com
}

\begin{abstract}
Knowledge sharing takes part in supporting the era of society 5.0. This study aims to investigate the role of perceived organizational support (POS), servant leadership, and organizational citizenship behavior (OCB) as the antecedents of knowledge sharing. The data were collected via an online questionnaire from 225 public sector employees in Indonesia. Structural equation modeling results indicate that OCB has a significant positive effect on knowledge sharing while also fully mediated POS and servant leadership's effect on knowledge sharing. However, no significant direct effect was found between POS and servant leadership on knowledge sharing. This paper's findings contribute to the establishment of knowledge sharing's antecedents' concept, especially in the public sector. Furthermore, this paper responds to the call for additional research concerning the consequences of OCB in the public sector.
\end{abstract}

Keywords: Organizational support, Servant leadership, Organizational citizenship behavior, Knowledge sharing, Public sector.

\section{INTRODUCTION}

Knowledge has become a strategic resource that is believed to play an essential role in supporting organizational performance (Masa'deh et al., 2016). Therefore, every organization needs to encourage knowledgesharing, which helps form new knowledge, complement old knowledge, and integrate more knowledge in the future (Masa'deh et al., 2016). As one of the fundamental activities of an organization (Ahmad \& Karim, 2019), knowledge sharing has been proven to support organizational sustainability (Cugueró-Escofet et al. 2019) with its positive influence on individual learning (Zhu 2017), work performance (Masa'deh et al.
2016), and team innovation (Cheung et al. 2016).

Not limited to the private sector, knowledge sharing is also seen as a vital factor in human resource management in public sector organizations which could function as a complementary mechanism to fill the knowledge gap among public sector employees (Tuan, 2016). This view is in line with the characteristics of public sector organizations known as knowledge-intensive organizations (Kim, 2018), considering the large amount of information continuously generated within organizations (Rasdi \& Tangaraja 2020). It is not surprising then that many research results confirm the positive influence of knowledge sharing on public sector organizations. Knowledge sharing is thought to be positively related to 
individual work performance (Tripathi et al. 2020), innovative work behavior (Khorakian et al. 2019), and organizational innovation (Al-Husseini \& Elbeltagi 2018).

Throughout time, knowledge sharing remains a crucial aspect for the organization, including in Society 5.0. Society 5.0 is a concept put forward by Japan as a humanoriented approach that aims to improve the quality of people's lives (Konno \& Schillaci 2021) by utilizing the potential that exists in Industry 4.0 (Pereira et al. 2020). Achieving these goals requires collaboration between the private and public sectors in solving social problems and creating a viable business environment (Roblek et al. 2020). Furthermore, the presence of a knowledge-intensive society as a crucial aspect of Society 5.0 (Deguchi et al. 2020) also demands the practice of sharing knowledge and information in creating new social values in it (Hysa et al. 2021). Thus, knowledge sharing at the internal organization is the first step to creating knowledge sharing practices with a broader Society 5.0.

According to the above discussion, identifying and managing the factors considered to be antecedents of knowledge sharing becomes critical for every organization. Based on the social exchange theory, knowledge sharing, which is the embodiment of positive interaction efforts, will be realized if only an individual receives an equal treatment or reward (Bock \& Kim, 2002; Cabrera \& Cabrera, 2005). At work, organizational support and leadership style become part of that interaction. Therefore, previous research also confirms the role of perceived organizational support (POS) and servant leadership as the antecedents of knowledge sharing.

POS, which can be interpreted as employees' perceptions of organizational care and appreciation for their contributions (Eisenberger et al. 1986), had been proven to have a positive effect on knowledge sharing (Cugueró-Escofet et al. 2019). On the other hand, servant leadership as a context for more minor interactions was also confirmed to positively affect knowledge sharing (Kadarusman \& Bunyamin 2021, Tripathi et al.
2020). Besides, previous research showed the role of organizational citizenship behavior (OCB) in the relationship between POS, servant leadership, and knowledge sharing. OCB is considered mediating the relationship of POS and servant leadership on knowledge sharing (Han et al. 2019; Tuan 2017).

Based on the previous explanation, this study aims to examine the role of POS, servant leadership, and OCB in predicting knowledge sharing, particularly in public sector organizations. In addition, the results could complement the lack of previous research concerning the consequences of OCB in the public sector (de Geus et al. 2020).

\section{RESEARCH METHODS}

This study used a self-administered questionnaire instrument in terms of data collection. The questionnaire contained 43 closedended questions on a six-point Likert scale compiled and distributed online (Google Forms) to be filled in anonymously and independently by respondents. The purposive sampling technique targeting specific criteria of people as information providers (Sekaran $\&$ Bougie, 2016) was used since the sample involved was 225 public sector employees. The questionnaire data was then processed and analyzed using a structural equation model (SEM).

Knowledge sharing is measured by four questions that adopted Lin (2007) with the sample question "I share my job experience with my co-workers." Meanwhile, OCB is determined using 24-item questions introduced by Podsakoff et al. (1990) to measure five dimensions of OCB with the sample question "I do not take extra breaks." Based on SL-7 developed by Liden et al. (2015), servant leadership is calculated through seven questions with the sample question "my leader emphasizes the importance of giving back to the community." Subsequently, POS is assessed by eight questions from the survey of perceived organizational support questions (Eisenberger et al., 1997) with the 
sample question "my organization cares about my opinions."

\section{RESULTS AND DISCUSSION}

As given in Table 1, the results of the measurement model test reveal that each variable in this study has AVE and CR values that exceed the minimum threshold for feasibility. An AVE value of more than 0.5 and a CR value of more than 0.7 indicate the adequacy level of convergent validity and construct reliability for the respective variable (Hair et al., 2019).

Table 1. AVE \& CR Values of Variables

\begin{tabular}{ccc}
\hline Variables & AVE & CR \\
\hline POS & 0.522 & 0.881 \\
Servant Leadership & 0.504 & 0.750 \\
OCB & 0.574 & 0.962 \\
Knowledge Sharing & 0.583 & 0.805 \\
\hline
\end{tabular}

Moreover, Table 2 shows the results of the goodness-of-fit test of the structural model, which estimates how well the theoretical structure formed describes the conditions represented by the research data (Hair et al. 2019). According to Hair et al. (2019), a model is said to have a decent level of fit if it meets 3 to 4 criteria, with the provision of at least one indicator for each index category, namely absolute fit indices, and incremental fit indices. Furthermore, the inclusion of $x^{2}$, degrees of freedom, CFI, and RMSEA will provide sufficient information to assess the level of suitability of a model (Hair, 2019).

Table 2. Goodness-of-Fit Test Results

\begin{tabular}{ccc}
\hline Criteria & Results & Remarks \\
\hline GFI & 0.88 & Marginal Fit \\
RMSEA & 0.075 & Good Fit \\
Chi Square & $2.25: 1$ & Good Fit \\
NFI & 0.93 & Good Fit \\
TLI & 0.95 & Good Fit \\
CFI & 0.96 & Good Fit \\
AGFI & 0.83 & Marginal Fit \\
PNFI & 0.64 & Good Fit \\
\hline
\end{tabular}

With most of the criteria being in the good fit category, it can be inferred that the developed model of this study has met the good fit criteria.

The results of the path analysis test are exhibited in Figure 1 below. The first hypothesis of this study states that POS has a significant and positive impact on knowledge sharing. The test results show that the path coefficient value between POS and knowledge sharing is positive (0.08) with a t-value of 0.84 . This value indicates that POS has no significant positive effect on knowledge sharing because the t-value does not satisfy the minimum requirement of significance, i.e., 1.645. This result means that an increase in the perception of organizational support will not significantly change the tendency of an individual's knowledge sharing, so the first hypothesis of this study is rejected. Similar results emerged in a study conducted by Swift \& Virick (2013), demonstrating no significant relationship between POS and knowledge sharing. They argued that the insignificant relationship between POS and knowledge sharing might occur due to several things. At a certain point, POS condition would no longer encourage reciprocal behavior from employees, while the extent of organizational support satisfaction could make them inattentive. Furthermore, they could perform other behaviors as reciprocal actions of organizational support, such as organizational commitment other than knowledge sharing.

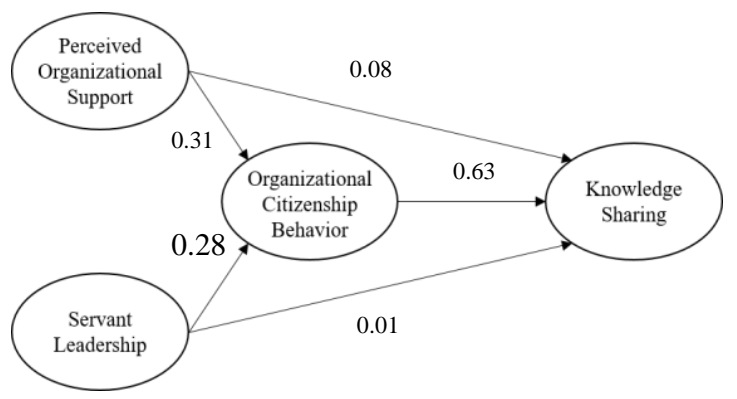

Figure 1. Path Analysis Results of Research Model 
A path coefficient value of 0.31 and a tvalue of 3.24 in the relationship between POS and OCB indicates the significance of POS's positive influence on OCB. The results support the second hypothesis of this study which states that POS has a significant and positive impact on OCB. These results may imply that the increasing perception of employees on organizational support will encourage these employees to manifest OCB. This is in line with a study by Han et al. (2019), showing a positive and significant effect of POS on OCB.

Furthermore, the third hypothesis of this study states that servant leadership has a significant and positive impact on knowledge sharing. As seen in Figure 1, the correlation between servant leadership and knowledge sharing is shown with a coefficient value of 0.01 and a $t$-value of 0.13 . The $\mathrm{t}$-value does not fulfill the minimum significance effect value (1.645), so the third hypothesis is rejected. These results explain that an increase in servant leadership by supervisors in the organization will not significantly affect the behavior of individual supervisors of employees. Indirectly, the results of this study are similar to Xie (2020). In this regard, servant leadership does not significantly impact organizational learning, which is closely related to an organizational learning culture, including the transfer of knowledge within organizations. Xie (2020) further reveals that the insignificant impact of servant leadership is caused by the cultural context of the Chinese state as an object of research that has a highpower distance. According to Hofstede (2011), Indonesia can be categorized as a country with high power distance characters; the same factors can then be used as the basis for the rejection of this hypothesis.

On the other hand, the path analysis results support the fourth hypothesis of this study which states that servant leadership has a significant and positive impact on OCB. It could be concluded from the value of the path coefficient (0.28) and the t-value (2.70), both of which exceed the limit of the significance value. Thus, it can be stated that the higher the embodiment of servant leadership performed by superiors in an organization, the greater the incentive for employees to behave in OCB. Previous studies also confirmed the same findings as a study carried out by Tuan (2017).

Figure 1 also reveals the significant and positive impact of OCB on knowledge sharing, which supports the fifth hypothesis of this study. The path coefficient value between OCB and knowledge sharing is 0.63 , with a t-value of 7.12, indicating that the value exceeds the minimum requirement of significance. Based on these results, it could be interpreted that knowledge sharing will increase along with an increase in OCB exhibited by employees. These results align with various previous studies, which also stated the positive and significant effect of OCB on knowledge sharing (Tuan, 2017).

As presented in Figure 1, the path coefficient of the indirect effect of POS on knowledge sharing through OCB $(0.195)$ has a larger and more significant value than that of the direct effect (0.08). It can be concluded that OCB mediates the effect of POS on knowledge sharing. The mediating role of OCB in this study is included in the category of indirect-only mediation or full mediation because the emergence of the effect of mediation is not accompanied by a significant direct effect (Zhao et al., 2010). Thus, the sixth hypothesis of this study, which states that OCB mediates the relationship between POS and knowledge sharing, is supported. Although they are not entirely the same, these results relate to a study done by Han et al. (2019), which states that OCB fully mediates the relationship between POS and knowledge sharing.

As explained earlier, Figure 1 also confirms the mediating role of OCB on the effect of servant leadership on knowledge sharing. The path coefficient value of the indirect effect of servant leadership on knowledge sharing through OCB (0.176) is greater and more significant than that of the direct effect of servant leadership on knowledge sharing (0.01). Hence, these results support the seventh hypothesis of this 
research, which states that OCB mediates the relationship between servant leadership and knowledge sharing. A study by Tuan (2017) shows identical results to this study where OCB has a significant mediating effect on the impact of servant leadership on knowledge sharing.

\section{CONCLUSION}

The results of this study provide organizations, especially the public sector, with a clearer picture of identifying the factors affecting knowledge sharing. POS, servant leadership and OCB were proven to influence knowledge sharing, aside from varying significance levels. This study confirms that OCB has a critical role in shaping knowledge sharing compared to POS and servant leadership. However, this does not mean that the roles of POS and servant leadership can be overlooked. It is evident that POS and servant leadership influence OCB before finally impacting knowledge sharing significantly. This implies that organizations need to set internal policies that provide both adequate support and motivation for their employees to intensify servant leadership at the managerial level. The enhancement of those two aspects will indirectly lead to knowledge sharing through OCB, thus allowing it to play a pivotal role in supporting the era of Society 5.0.

\section{REFERENCES}

Ahmad, F. and Karim, M. 2019. Impacts of knowledge sharing: a review and directions for future research. Journal of Workplace Learning 31(3): 207-230.

Al-Husseini, S. and Elbeltagi, I., 2018. The role of knowledge sharing in enhancing innovation: a comparative study of public and private higher education institutions in Iraq. Innovations in Education and Teaching International 55(1), pp.2333.

Bock, G.W. and Kim, Y.G., 2002. Breaking the myths of rewards: An exploratory study of atti- tudes about knowledge sharing. Information Resources Management Journal (IRMJ) 15(2):1421.

Cabrera, E.F. and Cabrera, A., 2005. Fostering knowledge sharing through people management practices. The International Journal Of Human Resource Management 16(5): 720-735.

Cheung, S.Y., Gong, Y., Wang, M., Zhou, L. and Shi, J., 2016. When and how does functional diversity influence team innovation? The mediating role of knowledge sharing and the moderation role of affect-based trust in a team. Human Relations 69(7): 1507-1531.

Cugueró-Escofet, N., Ficapal-Cusí, P. and TorrentSellens, J. 2019. Sustainable human resource management: how to create a knowledge sharing behavior through organizational justice, organizational support, satisfaction and commitment. Sustainability 11(19): 5419.

De Geus, C.J., Ingrams, A., Tummers, L. and Pandey, S.K., 2020. Organizational citizenship behavior in the public sector: A systematic literature review and future research agenda. Public Administration Review 80(2):.259-270.

Deguchi, A., Hirai, C., Matsuoka, H., Nakano, T., Oshima, K., Tai, M. and Tani, S., 2020. What Is Society 5.0?. In Society 5.0 (pp. 1-23). Singapore: Springer.

Eisenberger, R., Huntington, R., Hutchison, S. and Sowa, D., 1986. Perceived organizational support. Journal Of Applied Psychology 71(3):500507.

Eisenberger, R., Cummings, J., Armeli, S. and Lynch, P. 1997. Perceived organizational support, discretionary treatment, and job satisfaction. Journal of Applied Psychology 82(5): 812-820.

Hair, J. F., Black, W. C., Babin, B. J., \& Anderson, R. E. 2019. Multivariate data analysis (Eighth edition). Andover, Hampshire: Cengage.

Han, S.H., Yoon, D.Y., Suh, B., Li, B. and Chae, C., 2019. Organizational support on knowledge sharing: a moderated mediation model of job characteristics and organizational citizenship behavior. Journal Of Knowledge Management 23(6): 687-704.

Hofstede, G., 2011. Dimensionalizing cultures: The Hofstede model in context. Online readings in psychology and culture, 2(1): 2307-0919.

Hysa, B., Karasek, A. and Zdonek, I. 2021. Social media usage by different generations as a tool for 
sustainable tourism marketing in society 5.0 idea. Sustainability 13(3):1018.

Kadarusman, K. and Bunyamin, B., 2021. The role of knowledge sharing, trust as mediation on servant leadership and job performance. Management Science Letters 11(5): 1509-1520.

Khorakian, A., Mohammadi Shahroodi, H., Jahangir, M. and Nikkhah Farkhani, Z., 2019. Innovative work behavior in public organizations: The roles of ethical and knowledge sharing behaviors. Creativity Research Journal 31(2):164-173.

Kim, S., 2018. Public service motivation, organizational social capital, and knowledge sharing in the Korean public sector. Public Performance \& Management Review 41(1): 130-151.

Konno, N. and Schillaci, C.E., 2021. Intellectual capital in Society 5.0 by the lens of the knowledge creation theory. Journal of Intellectual Capital 22(3): 478-505

Liden, R.C., Wayne, S.J., Meuser, J.D., Hu, J., Wu, J. and Liao, C., 2015. Servant leadership: Validation of a short form of the SL-28. The Leadership Quarterly 26(2): 254-269.

Lin, C.P., 2007. To share or not to share: Modeling tacit knowledge sharing, its mediators and antecedents. Journal Of Business Ethics 70(4): 411428.

Masa'deh, R., Obeidat, B.Y.\& Tarhini, A. 2016. A Jordanian empirical study of the associations among transformational leadership, transactional leadership, knowledge sharing, job performance, and firm performance: a structural equation modelling approach. Journal of Management Development 35(5): 681-705.

Pereira, A.G., Lima, T.M. and Charrua-Santos, F., 2020. Industry 4.0 and Society 5.0: opportunities and threats. International Journal of Recent Technology and Engineering 8(5):3305-3308.

Podsakoff, P.M., MacKenzie, S.B., Moorman, R.H. and Fetter, R., 1990. Transformational leader behaviors and their effects on followers' trust in leader, satisfaction, and organizational citizenship behaviors. The Leadership Quarterly 1(2):107142.

Rasdi, R.M. and Tangaraja, G., 2020. Knowledgesharing behaviour in public service organisations: determinants and the roles of affective commitment and normative commitment. European Journal of Training and Development Vol. ahead- of-print No. ahead-of-print. https://doi.org/10.1108/EJTD-02-2020-0028

Roblek, V., Meško, M., Bach, M.P., Thorpe, O. and Šprajc, P., 2020. The interaction between internet, sustainable development, and emergence of society 5.0. Data 5(3):80.

Sekaran, U. and Bougie, R., 2016. Research methods for business: A skill building approach. Singapore: John Wiley \& Sons.

Swift, M.L. and Virick, M., 2013. Perceived support, knowledge tacitness, and provider knowledge sharing. Group \& Organization Management 38(6): .717-742.

Tripathi, D., Priyadarshi, P., Kumar, P. and Kumar, S., 2020. Does servant leadership affect work role performance via knowledge sharing and psychological empowerment?. VINE Journal of Information and Knowledge Management Systems. Vol. ahead-of-print No. ahead-of-print. https://doi.org/10.1108/VJIKMS-10-2019-0159

Tuan, L.T., 2016. How servant leadership nurtures knowledge sharing: The mediating role of public service motivation. International Journal of Public Sector Management. 29(1):91-108

Tuan, T. L., 2017. Knowledge sharing in public organizations: The roles of servant leadership and organizational citizenship behavior. International Journal of Public Administration 40(4): 361-373.

Xie, L., 2020. The impact of servant leadership and transformational leadership on learning organization: a comparative analysis. Leadership \& Organization Development Journal. 41 (2): 220236.

Zhao, X., Lynch Jr, J.G. and Chen, Q., 2010. Reconsidering Baron and Kenny: Myths and truths about mediation analysis. Journal Of Consumer Research 37(2):197-206.

Zhu, Y.Q., 2017. Why and how knowledge sharing matters for $\mathrm{R} \& \mathrm{D}$ engineers. $R \& D$ Management 47(2): 212-222. 